\title{
Conservation planning beyond giant pandas: the need for an innovative telecoupling framework
}

\author{
Fang Wang ${ }^{1,2^{*}} \&$ Jianguo Liu ${ }^{1}$ \\ ${ }^{1}$ Center for System Integration and Sustainability, Michigan State University, East Lansing MI 48823, USA; \\ ${ }^{2}$ Center for Nature and Society, Peking University, Beijing 100871, China
}

Received September 20,2016; accepted October 19,2016; published online December 21, 2016

Citation: Wang, F., and Liu, J. Conservation planning beyond giant pandas: the need for an innovative telecoupling framework. Sci China Life Sci $60,551-554$. doi: $10.1007 / \mathrm{s} 11427-016-0349-0$

Meeting human needs while sustaining ecosystems and the benefits they provide is a global challenge. A major barrier to achieve sustainable development goals is the lack of sufficient knowledge on the complex relationships between humans and nature (Loucks et al., 2001; Liu et al., 2007). Different parts of the world have never been as closely connected through all means of flows (e.g. information, labor, goods and products) as today. Such intensive interactions not only affect human systems, but also change natural systems (Leslie et al., 2015). However, these interactions and feedbacks were largely downplayed or ignored in conservation practices. Though the idea of developing conservation plans that involve local communities and related stakeholders has been advocated for decades, most practices were conducted at the local scale but ignoring the interactions between distant systems, and/or focused on few specific interests (e.g. firewood consumption, tourism, and etc.). Given this inadequate consideration of the critical interactions between human and natural systems, it is quite often that the practical applications benefit one or few targeting species but fail to support human needs, which may compromise conservation in the long run. Thus, it is critical to develop innovative systems approaches that improve human wellbeing while sustaining wildlife populations and their habitats.

The development and conservation efforts in and outside

*Corresponding author (email: wangfang.vic@gmail.com) giant panda nature reserves, a network consists of 67 protected areas across southwestern China, are perfect examples that local and national policies should benefit both conservation and society (Loucks et al., 2001). From the perspective of giant pandas, the species have been widespread throughout southern China and coexisted with human for thousands of years (Kong et al., 2016). This might have resulted from the traditional small-scale farming methods that have maintained extensive areas of high nature value in nearby mountainous areas (Pan et al., 2014). While the historical giant panda distribution might be a successful example of wildlife-human co-existence, the rapid developments were likely to underlie recent significant giant panda population declines in the past decades (Lu et al., 2001; State Forestry Administration, 2006). With the huge efforts on forest restoration and nature reserve establishment, now the wild giant panda population has recovered with a $16.8 \%$ population increase since 2003 (State Forestry Administration, 2015). From the human perspective, giant pandas and other natural resources are not just objects of admiration, but the essential elements that provide products, services, or land to meet the increasing livelihood needs for millions of people (Liu et al., 2016). As a result, the knowledge on the degree and direction how the natural and human systems interact with each other will provide critical information to help decision-makers to meet the long-term sustainable goals for both giant pandas and people (Pan et al., 2014; Liu et al., 2015). 
To obtain such knowledge, an innovative framework, telecoupling, is introduced to address central questions of how natural and human systems interact (Liu et al., 2015). The framework of telecoupling derived from the concept of Coupled Human and Natural Systems (CHANS), which are closed systems consist of five components (Residents, Policies, Forest, Wildlife and Contextual Factors, Figure 1, Liu et al. 2016 book chapter 2). While CHANS provide a standardized framework to describe closed systems, the telecoupling framework considers all systems are open ones, which enables researchers and decision-makers to measure linkages between distant CHANS (Liu et al., 2015). The telecoupling framework identified five major interrelated components: Systems (sending, receiving and spillover systems); Flows (move material, information, and energy among systems); Agents (facilitate the flows); Causes (drive the flows between systems); and Effects (result from the flows, Liu et al. 2016 book chapter 2). To expand previous concepts, the framework of telecoupling explicitly considers feedbacks and interactions across different levels and scales, which enable us to measure the complex linkages within and between CHANS at different scales (Liu et al., 2015; Liu et al., 2016).

Here we suggest using the telecoupling framework to facilitate integrated research and governance for conservation planning. We use coupled systems in and outside the giant panda nature reserve network in the Qinling Mountains (hereafter referred to as Qinling) as an example to demonstrate how to conduct integrated system approach for conservation and development purposes. A conceptual analytical schematic (Figure 2) is provided to demonstrate how the telecoupling framework works in Qinling.

To design a study within the coupled systems in Qinling, it requires researchers to collect data for both natural and human systems following interdisciplinary perspectives. When investigating the Local Resident subsystem in Qinling, researchers should focus not only on ordinary characteristics such as household size, age, and birth rate, but also need to measure the critical activities that are directly related to forest quality and wildlife dynamics. For example, the intensive farming and livestock production have negative impacts on giant panda distribution, while the off-farm work may reduce the local anthropogenic interference that finally contribute to species dispersal (Pan et al., 2014; Wang et al., 2015). For the Forest component, forest composition (e.g. primary or secondary), structure (e.g., understory species), and quality (e.g., continuous or fragmented) not only relate to conservation policies (e.g. of state or provincial forestry departments), but also contribute to resident income (e.g. Grain to Green compensation) and wildlife occurrence (e.g. existence of bamboo, habitat connectivity).

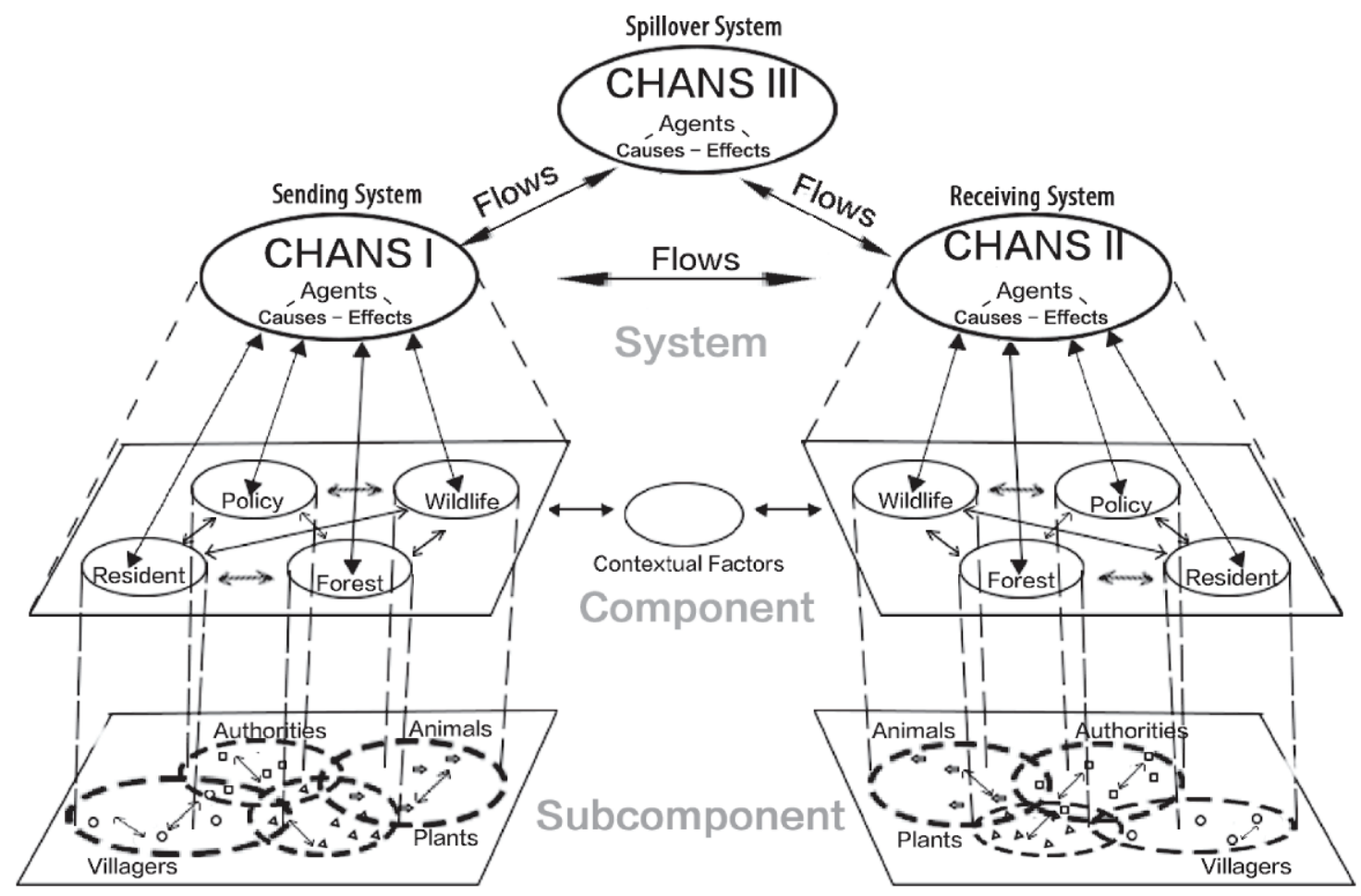

Figure 1 Diagram illustrating systems integration of telecoupling framework at different organizational levels. At the system level, the telecoupling consists of five major interrelated components: systems, agents, flows, causes and effects. At the component level within a CHANS, residents and policies belong to the human subsystem, forest and wildlife belong to the natural subsystem, and contextual factors exist in the focal coupled system and other systems. At the subcomponent level, interdisciplinary tools and techniques are required to fulfill the data demand. 


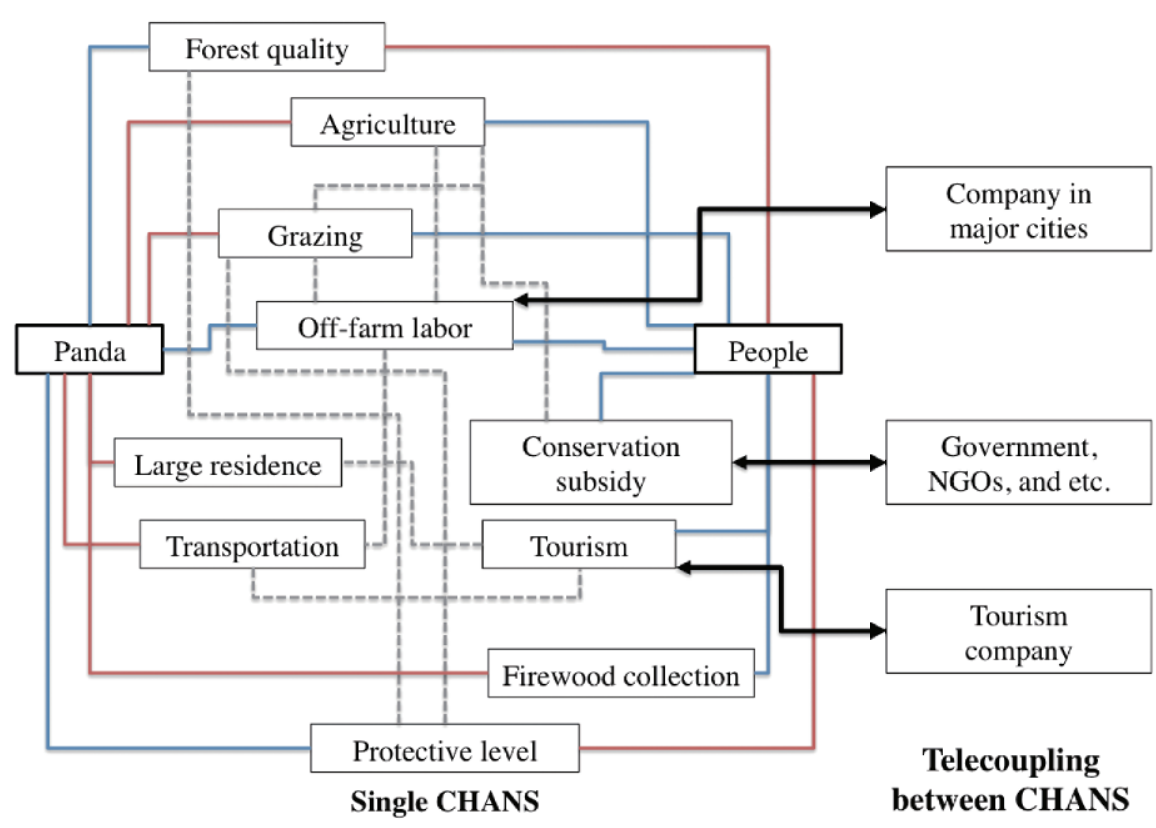

Figure 2 Conceptual analytical schematic that aims at measuring the shared needs and conflicts between giant pandas and people. Giant pandas and people may share positive (blue solid line) and negative (red solid line) associations with natural and socio-economic factors, and may have conflicts for certain factors (e.g. firewood collection). There could be correlations (gray dash line) between factors. The telecoupling processes (black arrow) are interactions between local and distant CHANS.

To move a step forward by measuring telecoupling processes between Qinling and outside systems, researchers are required to identify critical interactions and feedbacks across spatial boundaries between different systems. For example, Qinling sends clean water and forest products to Xi'an City, another CHANS, and receive financial payment in return. A more complicated case is tourism development. The existence of giant pandas provides precious opportunities for attracting tourists from other places. In 2015, Qinling received more than 500,000 tourists from Xi'an and other major cities. The fast tourism development significantly increased the net income of local residents and tourism companies, but also introduced disturbances to wildlife habitat (e.g. via increased transportation of people and goods, intensive human activities near giant panda habitat). In some regions the boosting anthropogenic interferences caused decrease in giant pandas distribution (Wang et al., 2014), which may negatively affect the tourism industry in the long run. By collecting information on the flows (e.g. number of tourists, amount of money), causes (e.g. distribution of scenery attractions), effects (e.g. increased financial income, decreased giant panda habitat quality) between different systems (e.g. Qinling, Xi'an City, and tourism agencies), and linking such results with the knowledge of giant panda habitat preference obtained at local scale, researchers could quantitatively evaluate the risks and benefits of tourism developments in Qinling. To summarize, the telecoupling framework provides a powerful tool when decision-makers need to meet human needs while sustaining ecosystems and the benefits they provide.
The data collection and analysis for operationalizing the telecoupling framework require the integration of interdisciplinary tools and techniques. For example, the data collection will involve diverse survey techniques including: (i) in-person interviews and surveys with households for the socioeconomic data (e.g. grazing intensity, off-farm work), (ii) remote sensing for the forest information (e.g. forest composition) and human activities (e.g. area of farmland), and (iii) field survey techniques such as camera trapping and sign transect surveys for wildlife data (e.g. panda distribution and activity pattern). For data analysis, traditional methods are still applicable but need to highlight the interactions between key components. Systems modeling is a widely used approach for integrating a variety of data and relationships. For example, agent-based models are an increasingly popular bottom-up modeling approach that incorporates detailed information about each object to understand emergent properties (Liu et al., 2016). Network analysis provides another nonparametric approach to understand more complex ecological and socioeconomic dynamics.

To demonstrate how the telecoupling framework works in Qinling, we provide a conceptual analytical schematic that aims at measuring the shared needs and conflicts between giant pandas and people (Figure 2). Network analysis provides a sound approach to link interdisciplinary modeling tools (e.g. species resource selection functions and socio-economic models). The telecoupling processes (e.g. tourism, off-farm working opportunity) can be measured between local and distant CHANS. To achieve sustainable conservation and development goals, positive interactions could lend 
themselves to build strategies across sectors, while the existence of negative interactions will be subject to trade-offs. Such information enables decision-makers to promote synergies and minimize the trade-offs.

The critical demand to strive for global sustainability requires a sound foundation for understanding the complex interactions in coupled human and natural systems. Through demonstrating the application of the integrated framework of telecoupling to evaluate human-wildlife interactions for future conservation planning in the Qinling Mountains, we believe that the framework as well as other integrated system approaches have strong implications beyond giant panda conservation.

Compliance and ethics The author(s) declare that they have no conflict of interest.

Kong, L., Xu, W., Zhang, L., Gong, M., Xiao, Y., and Ouyang, Z. (2016). Habitat conservation redlines for the giant pandas in China. Biol Conservation in press doi: 10.1016/j.biocon.2016.03.028.

Leslie, H.M., Basurto, X., Nenadovic, M., Sievanen, L., Cavanaugh, K.C., Cota-Nieto, J.J., Erisman, B.E., Finkbeiner, E., Hinojosa-Arango, G., Moreno-Báez, M., Nagavarapu, S., Reddy, S.M.W., Sánchez-Rodríguez, A., Siegel, K., Ulibarria-Valenzuela, J.J., Weaver, A.H., and Aburto-Oropeza, O. (2015). Operationalizing the social-ecological systems framework to assess sustainability. Proc Natl Acad Sci USA 112, 5979-5984. Liu, J., Hull, V., Yang, W., Viña, A., Chen, X., Ouyang, Z., and Zhang, H.
(2016). Pandas and People. (Oxford: Oxford University Press).

Liu, J., Dietz, T., Carpenter, S.R., Alberti, M., Folke, C., Moran, E., Pe11, A.N., Deadman, P., Kratz, T., Lubchenco, J., Ostrom, E., Ouyang, Z., Provencher, W., Redman, C.L., Schneider, S.H., and Taylor, W.W. (2007). Complexity of coupled human and natural systems. Science 317, $1513-1516$.

Liu, J., Hull, V., Luo, J., Yang, W., Liu, W., Viña, A., Vogt, C., Xu, Z., Yang, H., Zhang, J., An, L., Chen, X., Li, S., Ouyang, Z., Xu, W., and Zhang, H. (2015). Multiple telecouplings and their complex interrelationships. Ecol Soc 20, art44

Loucks, C.J., Lü, Z., Dinerstein, E., Wang, H., Olson, D.M., Zhu, C., and Wang, D. (2001). Ecology. Giant pandas in a changing landscape. Science 294, 1465-1465.

Lu, Z., Johnson, W.E., Menotti-Raymond, M., Yuhki, N., Martenson, J.S., Mainka, S., Shi-Qiang, H., Zhihe, Z., Li, G., Pan, W., Mao, X., and O'Brien, S.J. (2001). Patterns of genetic diversity in remaining giant panda populations. Conserv Biol 15, 1596-1607.

Pan, W.S., Lü, Z., Zhu, X., Wang, D., Wang, H., Long, Y., Fu, D., and Xin, Z. (2014). A Chance for Lasting Survival: Ecology and Behavior of Wild Giant Pandas. (Washington: Smithsonian Institution Scholarly Press).

State Forestry Administration P.R.C. (2015). Report of the Fourth National Giant Panda Census. (Beijing: Science Publishing House).

State Forestry Administration P.R.C. (2006). Report of the Third National Giant Panda Census. (Beijing: Science Press)

Wang, F., McShea, W.J., Wang, D., and Li, S. (2015). Shared resources between giant panda and sympatric wild and domestic mammals. Biol Conserv 186, 319-325.

Wang, F., McShea, W.J., Wang, D., Li, S., Zhao, Q., Wang, H., and Lu, Z. (2014). Evaluating landscape options for corridor restoration between giant panda reserves. PLoS ONE 9, e105086. 